\title{
The Complimenting Behavior of Iraqi College Students: Same-Gender Study
}

\author{
Jathla A. Mahmood ${ }^{1}$ \& Osamah M. Ali ${ }^{1}$ \\ ${ }^{1}$ College of Arts, Iraqi University, Baghdad, Iraq \\ Correspondence: Jathla A. Mahmood, College of Arts, Iraqi University, Baghdad, Iraq. Tel: 964-790-240-4360. \\ E-mail: jathla_ahmed@yahoo.com
}

Received: May 11, 2018 Accepted: June 18, 2018 Online Published: June 21, 2018

doi:10.5539/ijel.v8n5p238 URL: https://doi.org/10.5539/ijel.v8n5p238

\begin{abstract}
This study aims at finding out the similarities and differences in complimenting behavior of same-gender Iraqi college students: (male-male, and female-female). Eighty students (40 males, and 40 females) from the Iraqi University participated in the current study. The data is collected by using a questionnaire. The results show that men and women compliment in exactly the same frequencies. Women favor appearance as a compliment topic while men favor ability \& skill. Both men and women compliment mainly to strengthen relationships. Being from a city other than Baghdad proved to be an effective factor on some of the results. The results are analyzed, discussed, and compared to the work of previous researchers.
\end{abstract}

Keywords: Iraqi students, compliments, same-gender, frequencies, compliment topic, function

\section{Introduction}

The process of using a language or communicating with people is a complex behavior that requires both linguistic and pragmatic competence (Note 1). A speaker's choice of language is determined by the situation and the interlocutor which means that we are influenced by socio-cultural norms and constraints that affect the way we communicate whether in first or second language (Al Falasi, 2007).

One of the effective ways of communication is the use of compliments. Compliments have been said to 'grease the social wheels' and therefore work as 'social lubricants' which enable us to 'create or maintain rapport' (Wolfson, 1983). Holmes (1988a, p.485) defines compliments as 'a speech act which explicitly or implicitly attributes credit to someone other than the speaker, usually the person addressed for some 'good' (possession, characteristic, skill, etc.) which is positively valued by the speaker and the hearer'. A similar definition to that of Holmes is Coates' (1998, p.145): 'a compliment conveys, explicitly or implicitly, positive appreciation of something or action for which the addressee may apparently be credited: appearance, achievements, possessions.' It is also defined as 'an utterance containing a positive evaluation by the speaker to the addressee' (Wolfson, 1989, p. 220).

As can be seen from the definitions above, compliments can be given over a variety of topics i.e. appearance, possession, skill, etc. and are mostly viewed as serving a positive function. The most basic function of compliments is as positively polite speech act that is used to express interest in the hearer, offer solidarity and goodwill, and make the addressees feel good about themselves, their skills, etc. (Coates, 1998; Herbert, 1986, 1990; Holmes, 1988b; Monjezi, 2014). In addition to increasing solidarity, Holmes, following Brown and Levinson's politeness theory, proposed two more compliment functions. First, they serve as positive politeness strategies before a face threatening act (FTA). Second, they may act as face threatening acts (FTA's) themselves. In other words, compliments could be considered as an intrusion from the speaker onto the hearer.

Compliments are worldwide, daily used in different countries and cultures. Although they are culture universals, researchers have found that these compliments tend to vary considerably in formulas, responses and topics according to societies' socio-cultural norms (Farghal \& Al Khatib, 2001). With respect to the compliment topic, which is of concern to the current paper, Barnlund and Araki (1985) and Matsuura (2004) investigation of American and Japanese compliments shows that skill, work and study (i.e. achievement and ability) are the most frequently complimented attributes in Japan. Their studies also reveal that the Japanese tend to believe that complimenting someone is more difficult than what Americans think. Baek states that a person's conduct or 
moral behavior (i.e personality) is the most frequently complimented attribute in Korean society (cited in Kim, 2010). In Sun's (2013) critical literature review of compliments in China, it appears that appearance and performance are the most frequently praised. In another study of compliments, Monjezi (2014) states that appearance is the most frequent compliment topic among Iranian college students of English. To compliment someone on appearance seems to be most frequent in Arabic and English societies as well. This is evident in Nelson, El Bakary and Al Batal (1993) and Al Rousan, Awal and Salehuddin (2014) studies of Egyptian and Jordanian compliments and in Holmes' (1988a) study of New Zealand English and Knapp, Hopper, and Bell, (1984), Nelson et al. (1993) and Bolton (1994) studies of American English. It is also found that American compliments tend to be more frequent and more direct rather than indirect.

In addition to the differences in complimenting behavior across cultures, compliments and their topics are affected by the gender of both the speaker and hearer within the same country. For example, Petit (2006) study of French compliments in single-sex conversations reveals that females compliment each other mainly on appearance, abilities \& skills, and personality. On the other hand, male single-sex conversations didn't show even one compliment. In another study, Monjezi (2014) pairs of same-gender Iranian students show that women compliment significantly more than men do (32 to 15$)$ and that $(53 \%)$ of women's compliments were on appearance. Only (19\%) were on achievements and abilities; the topics which comprised (63\%) of the men's data of which only (14\%) was on appearance. Similar results are gained from studies on English compliments. In Holmes' (1988a) corpus of 484 New Zealand compliments, females paid significantly more compliments, most of which were on appearance, to each other (51\%) than males did to each other $(9 \%)$. Compliments on possession were dominant between males. Inspired by Holmes work, Bolton (1994) replicated that study on a smaller scale and in the United States. The results were very similar to those of Holmes with the exception that compliments on ability and performance were the dominant among U.S. males. Herbert (1990) and Parisi and Wogan (2006) collected a corpus of (1062) and (270) American compliments respectively. In both corpora, females complimented each other far more than what they did to men or men to each other. In the latter study, again, females' compliments were mainly on appearance (52\%) whereas males mostly praised skills (66\%). Looking at Arabs complimenting behavior, we can definitely see similar results. Al Rousan et al. (2014) and Qanbar (2012) analysis of (132) Jordanian compliments and (400) Yemini compliments show that the most frequent compliments occur in female-female interactions $(52 \%, 50 \%)$ than in male-male $(33 \%, 22 \%)$ or opposite gender interactions. In females interactions appearance was most frequently complimented whereas males mostly praised personality and ability. Another study on Arabic compliments is that of Nelson et al. (1993). Same results were gained from his corpus of (60) Egyptian compliments except for one interesting finding. Men gave more compliments to women and to each other than women did to themselves or to men. Given the literature review above, it seems that compliments taking place between males focus on personality, abilities, and skills whereas female-female compliments focus mainly on appearance.

Although many studies have been conducted on Arabic compliments the vast majority of that research is on compliment structure, responses, L1/L2 strategy transfer, and the effects of gender on these factors as in (Al Falasi 2006, Cuesta \& Ainciburu 2015, Drbseh 2015, Ebadi \& Salman 2015, Farghal \& Al Khatib 2001, Farghal \& Haggan 2006, Mahmood 2014, Mughazi 2000, Nelson, Al Batal \& Echols 1996, Salameh 2013). The very little research, at least to the best knowledge of the researchers, on the frequency, topic and function of Arabic compliments and none on Iraqi compliments motivated the current study. This study aims at empirically investigating the complimenting behavior among same-gender Iraqi college students of English in terms of topic and frequency and the effect of gender on them. To examine these same-gender compliments the following questions emerge:

1) What are the similarities and differences in the complimenting behavior of male-male, and female-female Iraqi college students in Iraq?

2) How similar or different is their behavior compared to that of previous research?

\section{Method}

The methodology used here is a multiple-choice questionnaire. Inspired by the work of previous researchers and the very goals of the current study, the questionnaire included three multiple-choice questions. Question one is designed to elicit data about the frequency of compliments that participants pay per-week. Question two inquires the participants to view the topics of compliments and select the one they mostly compliment their friends on. Concerning question three, it is intended to give data about the purpose/ function behind the compliments friends pay to each other. In all three questions, participants are asked to pick the choice that best reflects their natural complimenting behavior and are not allowed to choose more than one option per question. By the help of one of 
the instructors, the questionnaires are administrated to students during regular class sessions; using the last 15 minutes of third and fourth-year classes.

Despite the fact that almost all participants are students of English, the questionnaire is explained in both English and Arabic in order to avoid any misunderstanding that might happen. Another important issue to be mentioned here is that the participants are constantly reminded that they are supposed to be complimenting their same-gender friends (Note 2). When students get done with their answers, all papers are collected. The results gained from the participants' choices are shown and discussed in the following sections.

\section{Subjects}

The participants in this study are 80 students from Iraqi University, mostly from the Department of English, Fourth-year, as well as Third-year students. The 80 students are divided into 40 male students and other 40 female students. They are all similar in age (21-25). These participants are from Baghdad, except for 20 (10 male and 10 female students) who are from other cities and other departments (Arabic, Quran Science, and College of Law). The following table summarizes the subjects:

Table 1. The subjects

\begin{tabular}{lll}
\hline & City & \\
\cline { 2 - 3 } Gender & Baghdad & Other \\
\hline Males & 30 & 10 \\
Females & 30 & 10 \\
\hline
\end{tabular}

Subjects distribution according to their gender and city of origin.

\section{Results}

The data collected for the first research question is to be analyzed in terms of frequency, type, and purpose/ function of compliments each separately.

Starting with compliment frequencies, it is very surprising to see that both men and women had the exact same results. The results reveal that the most frequent answer among them is 1-3 times per week ( $40 \%)$. The second most frequent answer was none and 3-6 times per week constituting (20\%) of the data for each. The rest of the answers were for more followed by 6-9 times per week. The following figure summarizes the frequencies of males' and females' compliments.

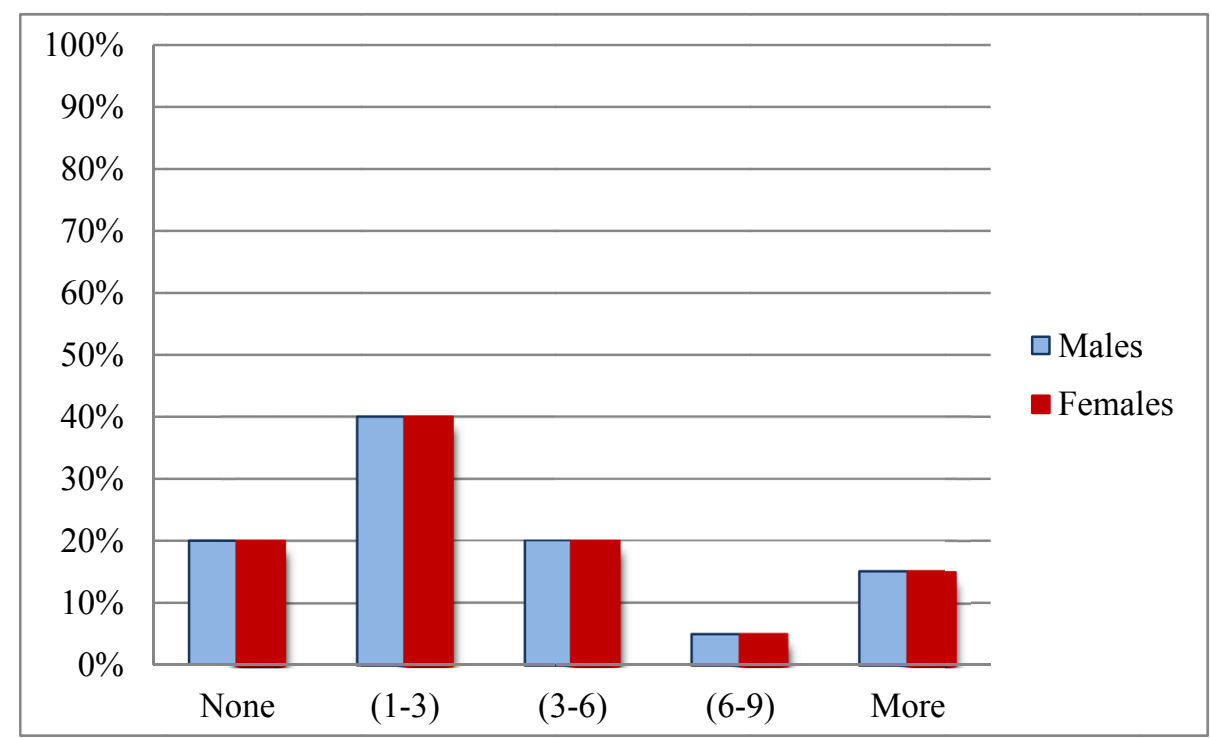

Figure 1. The distribution of data according to the frequency of compliments 
As to the topics of compliments, male students seem to compliment their same-gender friends mostly on ability \& skills $(50 \%)$ followed by appearance, then, personality \& ethics with relatively similar rates, and finally possession. On the other hand, female students compliment their same-gender friends on appearance (56\%) in the first place, ability \& skills and personality \& ethics in the second place with exactly the same rates. Finally, like male students, possession comes last in the list for females. Figure two below summarizes these results.

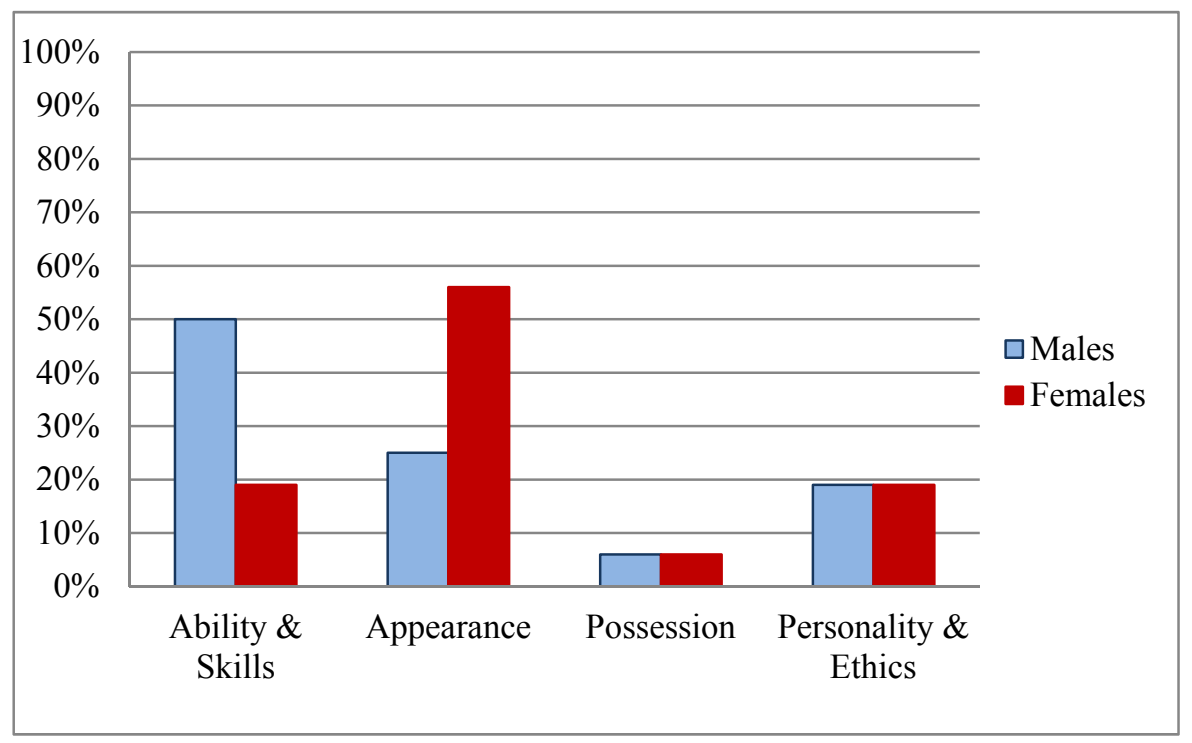

Figure 2. The distribution of data according to the topic of compliments

Considering the purpose behind compliments, we can see that both males and females compliment their same-gender friends mostly because they are comfortable with ... to strengthen friendship relations (Note 3) (70\% $\& 47 \%$ ) respectively. For females, giving positive feelings comes next (17\%) followed by expressing admiration and giving the compliment back at the same rates. For males, giving the compliment back comes second (12\%) leaving the rest of other options, excluding other, at exactly the same rate. For a full summary of the above mentioned results, see figure three below:

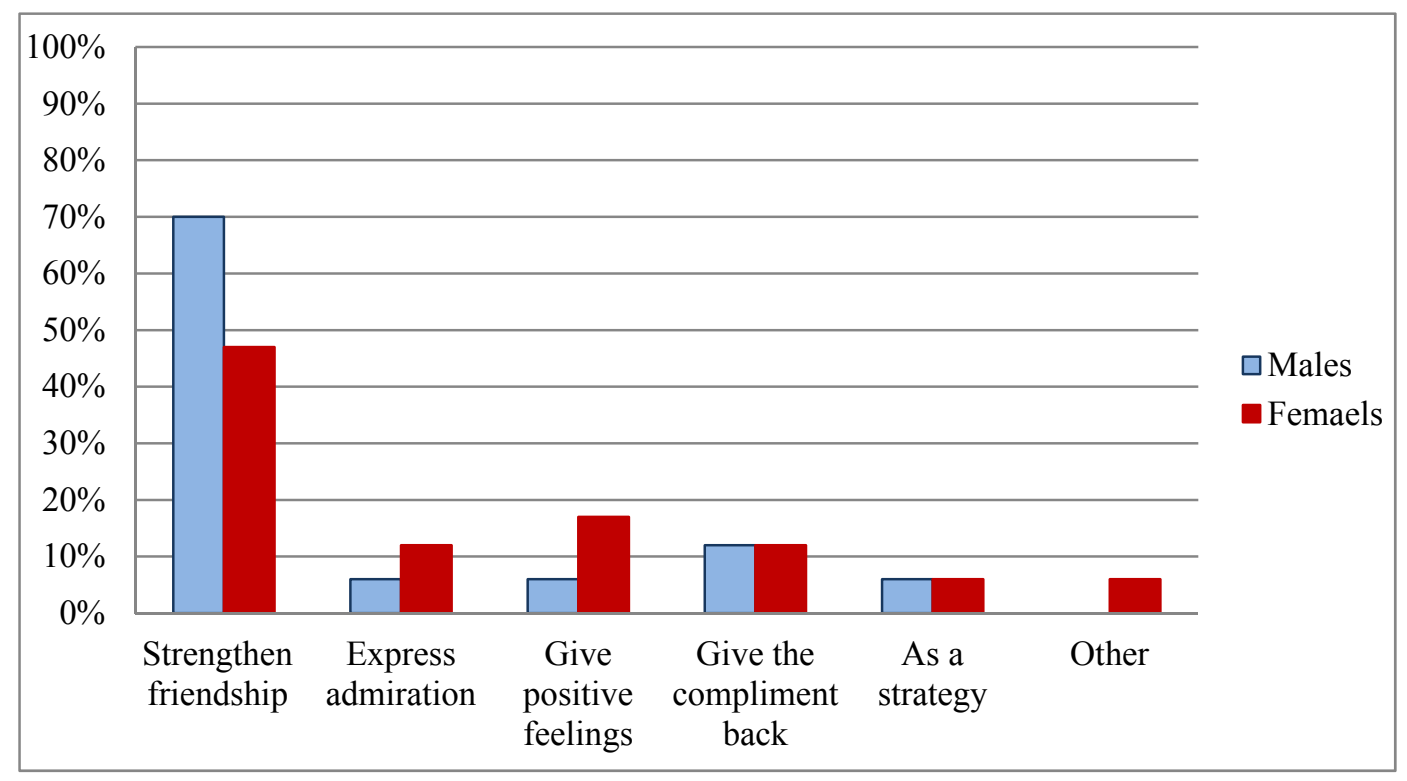

Figure 3. The distribution of data according to the reasons behind compliments 
The fact that some students come from cities other than Baghdad doesn't seem to be an effective factor neither on frequencies nor purpose of compliments for both male and female students. Here the distribution of results is similar to that of students from Baghdad. Yet, for male students only, this factor seems to be very effective on their choice of the type of compliment. Male students whose city of origin is other than Baghdad compliment each other mainly on personality \& ethics as is shown in the figure below:

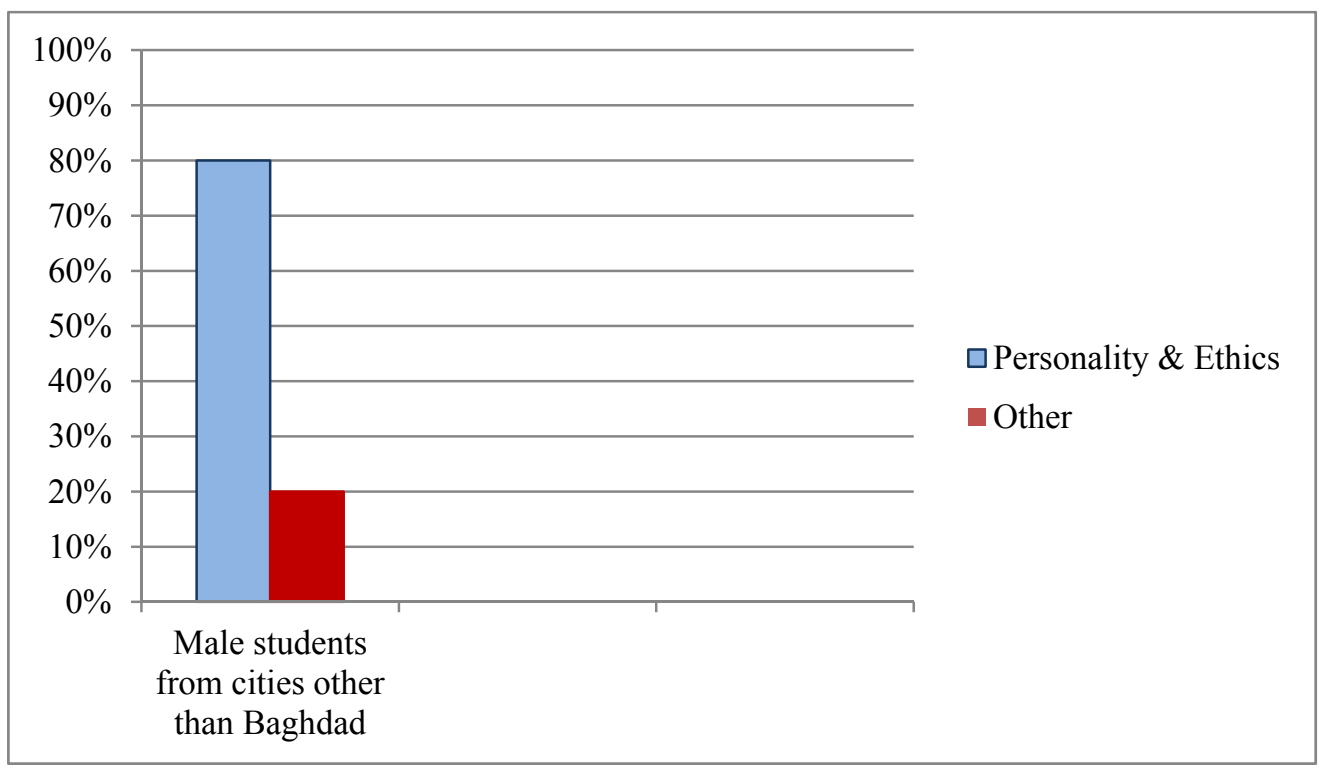

Figure 4. The distribution of data according to city of origin and type of compliment

\section{Discussion}

It is clear from the results above that Iraqi college students tend to have a rather different complimenting behavior among same-gender friends. The only finding that may look surprising at first is the similar frequencies. A second look at the frequencies shows that they are logical given the fact that compliments in Arab societies are viewed differently according to gender. In other words, in Arab societies, a woman is less likely to accept a compliment from a man unless that man is a family member or a very close friend. Otherwise, that compliment will just be ignored by the woman (Al Falasi, 2007). Given this fact, it makes it expected that more compliments will occur between same-gender friends than between opposite-gender friends as is shown by some studies of compliments among Arabs that are reported in the introduction section above.

The results concerning the topics of compliments in the current study correspond to those of previous researchers. Like in other societies, appearance is the most dominant topic among females in Iraqi society. This might raise the question of why women are complimented more on appearance? One reason which we believe to be far more effective is the surrounding environment. Whether in Western or Eastern societies, we can easily see the focus on women appearance compared to that of men. Starting with clothing brands to personal care products, perfumes and accessories, all are directed to women in the first place. As a result and away from any personal viewpoints, it goes without even noticing that both women and men focus on a woman's appearance in the first place. So, women are socially expected to place high value, and they do place high value, on appearance (Parisi \& Wogan, 2006 \& Qanbar, 2012). Beauty and the way they look means a lot to females. This, in return, explains why ability \& skills and personality \& ethics came in second place for them.

On the other hand, compliments between males are mainly on ability \& skills. Here, again, this result can be explained in terms of social environment/ values. Men seem to praise and like to be praised for skills, achievements, and personality. So, they are socially expected to value skill more. Since compliments are given for attributes that are highly valued by the listeners, it makes it logical that men give/ receive more compliments on their skills and abilities (Parisi \& Wogan, 2006 \& Qanbar, 2012). In addition, for the current study, being students in a competitive environment like college where one needs to prove himself may have also affected their choice. 
Another thing to be mentioned about the topics of compliments is that possession came last for both male and female students. The result supports Holmes (1988a) point of view. According to her, to compliment someone on possession could be face threatening. It may be understood as expressing a desire for the object that is being complimented.

As is shown by the results above, one factor that is very effective on male students choice of compliment topic is the city where those males come from/live. In Iraqi society, and some other Arab countries we believe, people from cities other than the capital (or a city that is as urban as the capital) place greater value on personal traits and ethics. Families raise their boys emphasizing on manhood qualities. To be a real man you are expected to be highly responsible, respectful, strong and courageous. Other more important qualities include honesty, integrity, word/promise keeping and maintaining good reputation; a matter which explains the results gained here. Having said so, this doesn't mean that families in Baghdad don't pay attention to such qualities. But, being in a more open more competitive community in the capital makes other things like ability \& skill and appearance as important as personal traits \& ethics.

All students in this study, males and females, use compliments to strengthen friendship relations in the first place. This finding supports Holmes (1988a) claim that the most basic function of a compliment is as positively effective speech act that is used to increase solidarity between speakers. The finding is further supported by the students choice of compliment topics that attends to the positive face needs of each. For men, ability \& skills is what they like to be praised for. For women, appearance is a topic that is least threatening, most appropriate and gratuitous among equals like friends. It is a positively effective speech act that cannot be interpreted other than an expression of solidarity (Holms, 1988b, Parisi \& Wogan, 2006 \& Qanbar, 2012). Another interesting finding here is the second choice of both male and female students. For females, another function of a compliment is to give positive feelings to the addressee. On the other hand, males just seem to be obliged to give a compliment back. This, once again, supports Holmes (1988b) claim that women view compliments as positive means to maintain good relations whereas men may consider them as embarrassing or face threatening acts. In general, women care about feelings, their own as well as others', more than men do. They are not embarrassed to talk about/express their feelings which by itself may make them feel positive. Unlike women, men are more practical, less emotional and more conservative when it comes to expressing feelings. Wu L. (2008, p.32) states that "though they also make compliments, they mostly do it only when it is necessary. They are not like females who express their feelings through compliments just like the daily life occurrences with no specific intentions. For males to give and receive compliments will sometimes threaten their face."

\section{Conclusion}

In conclusion, it is obvious that there are some similarities and differences in the complimenting behavior of Iraqi male and female college students and when compared to that of previous research. One interesting finding is that both men and women complimented each other in exactly the same rates which is different from the results obtained in most previous research where women use compliments far more than men do. However, like previous researchers, in the current study we find that women mainly favor appearance as a topic for their compliments whereas men are mainly in favor of ability \& skill. This result is logical and expected when taking the surrounding environment into consideration. "Since society places different weighs on these qualities for males and females,... these social norms translate into discrepancies in compliment topic distributions." (Parisi \& Wogan, 2006, p.25). As to the function of compliments, both male and female students confirm the statement that compliments main function is as an effective speech act that strengthens relations and expresses solidarity. By their second function choices, they also confirm the claim that women attend to positive face needs while some men consider compliments as face threatening.

Finally, it should also be mentioned here that these results have been gained by means of a questionnaire, not natural everyday speech; a factor which could have had an effect on the results obtained.

\section{Acknowledgment}

Many thanks are due to Miss Rana N. Aziz for sparing us time from her classes with the third and fourth-year students at the Department of English and for proofreading the finished article.

\section{References}

Al Rousan, M. Y., Awal, N. M., \& Salehuddin, K. (2014). Gender differences in topics and forms of compliment among Jordanian students in Malaysia. Journal of Language and Communication, 1(2), 125-136.

Al-Falasi, H. (2007). Just say "Thank you": A study of compliment responses. The Linguistic Journal, 4(1), $28-42$. 
Barnlund, D., \& Araki, S. (1985). Intercultural encounters: The management of compliments by Japanese and $\begin{array}{lllll}\text { Americans. Journal of Cross-cultural Psychology, } & \text { 16(1), }\end{array}$ https://doi.org/10.1177/0022002185016001002

Bolton, S. (1994). Influence of gender on compliment exchange in American English. Technical Research, 1-46.

Coates, J. (1998). Language and gender: a reader. Oxford: Blackwell.

Cuesta, A. R., \& Ainciburu, M. C. (2015). Transfer of Arabic formulaic courtesy expressions used by advanced Arab learners of Spanish. Procedia - Social and Behavioral Sciences, 173, 207-213. https://doi.org/10.1016/j.sbspro.2015.02.054

Drebseh, MM. H. (2015). The use of English compliments and compliment responses by the Arab students at Jordan university in Jordan. International Journal of Scientific and Research Publications, 5, 230-235.

Ebadi, S., \& Salman, A. R. (2015). Using compliment responses in Arabic and English: Focusing on male and female EFL learners in Iraq. Journal of Applied Linguistics and Language Research, 2, 157-178.

El Samaty, M. (2005). Helping foreign language learners become pragmatically competent. Proceedings of the $10^{\text {th }}$ TESOL Arabia Conference, 9, 341-351.

Farghal, M., \& Al Khatib, M. (2001). Jordanian college students' responses to compliments: A pilot study. Journal of Pragmatics, 33, 1485-1502. https://doi.org/10.1016/s0378-2166(01)00006-6

Farghal, M., \& Haggan, M. (2008). Compliment behavior in bilingual Kuwaiti college students. International Journal of Bilingual Education \& Bilingualism, 9(1), 94-118. https://doi.org/10.1080/13670050608668632

Herbert, R. K. (1986). Say "thank you"_ or something. American Speech, 61, 76-88. https://doi.org/10.2307/454710

Herbert, R. K. (1990). Sex-Based Differences in Compliment Behavior. Language in Society, 19(2), 201-224. https://doi.org/10.1017/s0047404500014378

Holmes, J. (1988a). Compliments and compliment responses in New Zealand English. Anthropological Linguistics, 28(4), 485-508.

Holmes, J. (1988b). Paying compliments: A sex-preferential politeness strategy. Journal of Pragmatics, 12, 445-465. https://doi.org/10.1016/0378-2166(88)90005-7

Holmes, J. (1996). Women, Men, and Politeness. London: Longman. https://doi.org/10.1017/s0272263100015278

Kim, H. J. (2010). A study of compliments across cultures: the effect of sociolinguistic transfer on EFL learners. Korea: Korea University.

Knapp, M. L., Hopper, R., \& Bell, R. A. (1984). Compliments: A descriptive taxonomy. Journal of Communication, 34, 12-31. https://doi.org/10.1111/j.1460-2466.1984.tb02185.x

Mahmood, J. (2014). Arabic compliment responses: A transfer of strategies? Midad Al Adab Journal, 9 , 679-694.

Matsuura, H. (2004). Compliment-giving behavior in American English and Japanese. JALT Journal, 26(2), 147-170.

Meyerhoff, M. (2006). Introducing sociolinguistics. New York, NY: Routledge. https://doi.org/10.4324/9780203966709

Monjezi, M. (2014). The effects of proficiency and gender on the compliments and compliment responses made by Iranian EFL learners. International Journal of Language Learning and Applied Linguistics World, 5(1), 625-636.

Mughazi, M. A. (2000). Pragmatics of the evil eye in Egyptian Arabic. Studies in the Linguistic Sciences, 30(2), 147-157.

Nelson, G. L., El Bakary, W., \& Al Batal, M. (1993). Egyptian and American compliments: A cross-cultural study. International Journal of Intercultural Relations, 17, 293-313. https://doi.org/10.1016/0147-1767(93)90036-8

Nelson, G., Al Batal, M., \& Echols, E. (1996). Arabic and English compliment responses: Potential for pragmatic failure. Applied Linguistics, 17(4), 412-432. https://doi.org/10.1093/applin/17.4.411

Parisi, C., \& Wogan, P. (2006). Compliment topics and gender. Women \& Language, 29(2), 21-28. 
Petit, E. (2006). Compliments and gender in French single-sex friendship groups. Occasional Papers Advancing linguistics, 7, 1-16.

Qanbar, N. (2012). Compliments in the Yemeni society: A sociolinguistic perspective. GEMA Online ${ }^{\mathrm{TM}}$ Journal of Language Studies, 12(3), 999-1017.

Salameh, A. (2013). Compliment responses in American English, Saudi Arabic and the English of Saudi EFL learners. Ann Arbor, MI: ProQuest.

Sun, N. (2013). Gender-based differences in complimenting behavior: A literature review. ANU Undergraduate Research Journal, 5, 213-222.

Wolfson, N. (1983). An empirically based analysis of complimenting in American English. In N. Wolfson \& E. Judd (Eds.), Sociolinguistics and Language Acquisition (pp. 82-95). New York, NY: Newbury House Publishers.

Wolfson, N. (1989). The social dynamics of native and nonnative variation in complimenting behavior. In M. R. Eisenstein (Ed.), The dynamic interlanguage: Empirical studies in second language variation (pp. 219-235). New York: Springer Science+ Business Media. https://doi.org/10.1007/978-1-4899-0900-8_14

Wu, L. (2008). Gender Based Differences in Compliments in the American Comedy TV-series Ugly Betty. Unpublished.

\section{Notes}

Note 1. According to Meyerhoff (2006), pragmatic competence is "the ability of a well-socialized speaker to know when certain speech acts are required, appropriate or inappropriate. A competence required over and above grammatical competence in order to successfully participate as a member of speech community" (p.96-7). It is also defined as "the ability to use language effectively in order to understand language in context" (El Samaty, 2005, p.341).

NOTE 2. Even though the current study is concerned with same-gender compliments, it would be very interesting to conduct another study on opposite gender compliments. Being Iraqis ourselves and our knowledge of the Iraqi society, we expect a very low frequency of compliments from females to males. According to Al Falasi (2007), women in UAE may even ignore male's compliments to them unless he is familiar enough; which we assume holds true in Iraq as well. So, if females ignore a male's compliment, how frequently would they compliment males?!

Note 3. To read the multiple choices in full see Appendix A.

\section{Appendix A}

\section{Gender:}

Age:

\section{City where you live:}

1- How many times per week do you compliment your same-gender friend?
a) None
b) $1-3$
c) 3-6
d) $6-9$
e) More

2- What do you compliment your same-gender friend mostly on?

a) Ability \& skills (A well-done job, gaming/ cooking skills, etc.)

b) Appearance (clothing and hair)

c) Possessions (objects owned by the addressee; a watch, handbag, etc.)

d) Personal traits and ethics. (being nice, intelligent, etc.)

3- Why do you pay compliments to your same-gender friend?

a) Being comfortable with, and close to them, just make it happens spontaneously to strengthen friendship relations.

b) To express admiration and interest.

c) To give positive feelings and energy to the addressee. 
d) You don't like getting compliments, but because they usually compliment you, so you have to give it back.

e) You use compliments as a strategy to ask for something else.

f) Other, please specify

\section{Copyrights}

Copyright for this article is retained by the author(s), with first publication rights granted to the journal.

This is an open-access article distributed under the terms and conditions of the Creative Commons Attribution license (http://creativecommons.org/licenses/by/4.0/). 